\title{
Serial verb constructions and the syntax-prosody interface
}

\author{
Matthew Tyler $^{1}$ (D) Itamar Kastner $^{2}$
}

Received: 2 June 2020 / Accepted: 27 January 2021 / Published online: 10 February 2021

(C) The Author(s) 2021

\begin{abstract}
Rolle (2020) identifies an apparent morphophonological conspiracy in serial verb constructions (SVCs) in Degema. He argues that it constitutes evidence for a partly-unified postsyntactic module, in which morphology and prosody are built in parallel (by 'Optimality-Theoretic Distributed Morphology'). We argue that the pattern Rolle identifies in Degema SVCs instead results from the simultaneous interaction of two independently-attested syntax-prosody phenomena: (1) the pressure for adjacent verbs in an SVC to form a single prosodic unit, and (2) the suppression of redundant agreement within a single prosodic word (a.k.a. 'Kinyalolo's Generalization'). Thus the Degema SVC conspiracy can be localized to the syntax-prosody interface, and there is no need to adopt a unified postsyntactic morphology-prosody module like Rolle's. We offer some further conceptual critiques of his model.
\end{abstract}

Keywords Clitics $\cdot$ Syntax-prosody $\cdot$ Degema $\cdot$ Serial verb constructions

\section{Introduction}

Rolle (2020) describes an interaction between morphology and prosody in serial verb constructions (SVCs) in Degema (Niger-Congo, Nigeria). He argues that this inter-

IK was supported in part by DFG award AL 554/8-1 (Gottfried Wilhelm Leibniz Prize 2014 to Artemis Alexiadou).

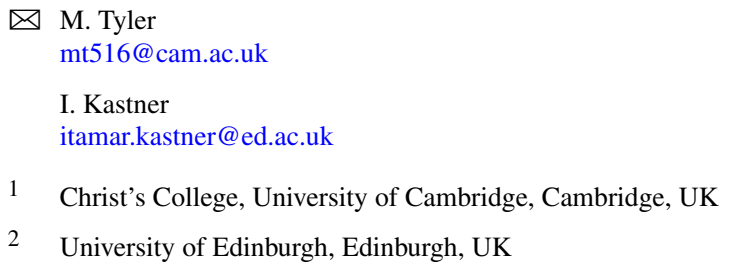


action can only be captured under an 'OT-DM' model (Optimality-Theoretic Distributed Morphology) which abandons traditional serial morphological derivations, and holds that syntactic structures are morphologized and prosodified in parallel, within a unified postsyntactic module. We propose an alternative analysis, which deconstructs the Degema pattern into two components, both of which are housed at the syntax-prosody interface, and both of which are attested independently in various languages.

The first component relates to the prosodic profile of SVCs cross-linguistically: adjacent verbs in an SVC (forming a contiguous SVC) will form a single prosodic unit, while non-adjacent verbs (a non-contiguous SVC) will not. The second component of our analysis relates to a dispreference for word-internal repetition of functional morphology: following work by Kinyalolo (1992), Carstens $(2003,2005)$ and others, we refer to this phenomenon as Kinyalolo's Constraint. We contend that both of these patterns are observed in Degema, and that the interaction identified by Rolle is simply both patterns surfacing simultaneously. Because the two components of the Degema pattern are found independently in the world's languages, they each require an independent formal explanation. This contrasts with Rolle's own analysis, in which the prosodic 'clustering' of adjacent verbs in a SVC is expected to be found only in languages with agreement marking.

Our analysis therefore shows that the Degema pattern can be captured with a serial morphological module feeding a parallel (OT-based) syntax-prosody mapping module, and does not merit the introduction of the fully-parallel morphology-prosody module of Rolle (2020). In addition, we show how SVCs, at least in some languages, require a unique treatment at the syntax-prosody interface, which has thus far gone unrecognized, and has remained accordingly undertheorized.

We present the Degema generalizations in Sect. 2, followed by the syntactic assumptions made by OT-DM and by us (Sect. 3). Sect. 4 introduces our analysis of the facts, which is to be contrasted with the OT-DM analysis in Sect. 5. Sect. 6 concludes.

\section{The Degema pattern}

\subsection{Proclitics and enclitics}

In Degema, a Niger-Congo language of Nigeria that is documented and analyzed extensively in Kari (2004), verbs can be bookended by both proclitics and enclitics. Proclitics are obligatory and agree with the subject in person, number and $+/$-human features. They come in two sets, and the choice between set 1 and set 2 is determined by the tense and polarity of the clause. Enclitics are used to mark perfect and factative aspect. Example (1) shows a verb with both a proclitic and an enclitic, as well as a direct object. Degema is an SVO language, so the object DP follows the verb complex. Our description relies primarily on data in Rolle (2020), whose original example numbers are cited (Rolle himself draws, in part, on Kari 2003, 2004 and other publications by Ethelbert Kari). 
(1)
Ohoso [o- sá - -n ] ẹ̣nám
Ohoso 3SG.SET2- shoot-FAC animal
'Ohoso shot an animal.'

Heavy (disyllabic) object pronouns behave like full object DPs, in that they also appear after the verbal complex, shown in (2).

$$
\begin{aligned}
& \text { Osoabo [o- kótú -n ] óyi } \\
& \text { Osoabo 3SG.SET2- call -FAC him/her } \\
& \text { 'Osoabo called him/her.' }
\end{aligned}
$$

Light (monosyllabic) object pronouns, in contrast, intervene between the lexical verb and the enclitic, as in (3).

$$
\begin{aligned}
& \text { [ o- kótú wọ́ -ōn ] } \\
& \text { 3SG.SET2- call you -FAC } \\
& \text { 'He/she called you.' }
\end{aligned}
$$

\subsection{Serial verb constructions}

Degema has serial verb constructions, on which see Kari (2003, 2004). Their relevant property for our purposes is that they show an interesting interaction with the cliticization pattern outlined above. When the verbs in an SVC are not interrupted by a full object DP, as in (4), the proclitic attaches to the front of the entire SVC, and the enclitic to the end of it. Note how the light pronoun in (4c) "incorporates" into the SVC.

$$
\begin{aligned}
& \text { a. Ohoso [ọ- tá dé -n ] isen } \\
& \text { Ohoso 3SG.SET2- go buy-FAC fish } \\
& \text { 'Ohoso went and bought fish.' } \\
& \text { b. ovóinú [mi- ḍ́w } t_{\mathrm{i}} \text { tạ́ -an ]? } \\
& \text { who that 1SG.SET2- follow go -FAC } \\
& \text { 'Who did I go with?' } \\
& \text { c. Breno [o- dúw mé tạ́ -ān ] } \\
& \text { Breno 3SG.SET2- follow me go -FAC } \\
& \text { 'Breno went with me.' }
\end{aligned}
$$

When SVCs show this pattern, which Rolle (2020) calls the single-marking pattern, they also display a notable phonological property: the entire SVC (excluding the proclitics and enclitics) forms a single domain for tone spreading (Rolle 2020:Sect. 4.4).

In contrast to the single-marking pattern, when the verbs in an SVC are interrupted by a full DP object or a heavy object pronoun (cf. (2)), each verb is bookended by its own proclitic and enclitic, as in (5). Rolle (2020) refers to this as the double-marking pattern.

$$
\begin{aligned}
& \text { a. [mi- ḍuw -n ] ọyi [mị- tá -ān ] } \\
& \text { 1SG.SET 1- follow -FAC her/him 1SG.SET1-go -FAC } \\
& \text { 'I went with him/her.' }
\end{aligned}
$$



b. Tatane [o- sá -n ] ệnám [o- gbíyé -ēn ]
Tatane 3SG.SET2- shoot-FAC animal 3SG.SET2-kill -FAC 'Tatane shot and killed an animal.'

In double-marking SVCs, the intervening object is not part of the domain of tone spreading.

Rolle argues that the single vs. double-marking pattern can only be captured by evaluating morphological outputs in parallel, providing evidence against a serial morphological derivation-see Sect. 5. In the next sections we present our own account of the pattern, which retains a classical, serial morphological module. We argue that the 'conspiratorial' appearance of the single vs. double-marking pattern emerges not during the morphological computation, but at the interface with prosody, a part of the grammar which has long been analyzed as involving parallel computation.

\section{Serial syntax and morphology}

We propose an analysis in which responsibility for the single- vs. double-marking pattern in Degema SVCs lies with the mapping from (morpho)-syntax to prosody. The intuition behind our account is that during the morphological derivation, every lexical verb in an SVC is supplied with some morphological nodes which, if exponed, would realize the agreement proclitics and aspect enclitics (in essence, double marking as default). Then, at the prosodification stage, these terminals may go unexponed, thanks to the influence of two high-ranked syntax-prosody mapping constraints.

Each of the two constraints is motivated by a cross-linguistically well-attested phenomenon. One constraint embodies the pressure to create single prosodic words out of unbroken verb chains in SVCs-something familiar from the typological literature on SVCs, albeit undertheorized. The other constraint embodies the pressure against having redundant functional morphemes within a single prosodic word, a phenomenon often described and analyzed under the name Kinyalolo's Generalization or Kinyalolo's Constraint. In some Degema SVCs, these constraints are pitted against each other, and the only way for the grammar to simultaneously satisfy them both is to sacrifice the exponence of SVC-internal clitics.

This section first provides a syntactic analysis (Sect. 3.1) and a morphological analysis (Sect. 3.2) of SVCs in Degema. Here we hew fairly closely to Rolle's (2020) own analysis. Sect. 4 then turns to the prosodification of SVCs. This is, we argue, where the single- vs. double-marking alternation arises.

\subsection{Syntax}

Following Collins (1997, 2002), Rolle (2020) assumes that SVCs consist of nested vP shells, where one lexical verb selects the next vP as its complement, as in (6). We adopt his syntactic structure in its entirety. 
(6)

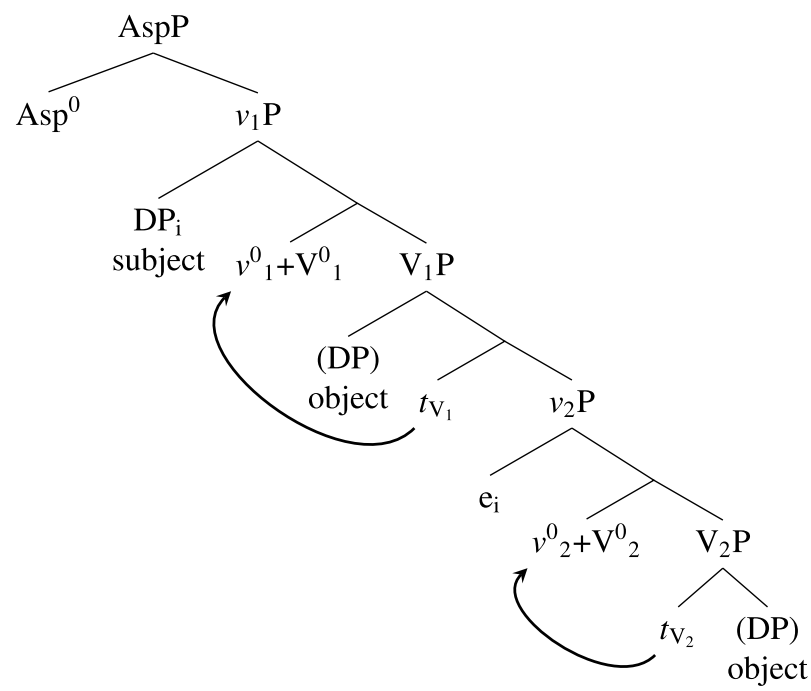

Following Rolle, we also assume that lexical verbs undergo head-movement to become a complex head with their associated $v$, thus deriving the fact that the first verb in an SVC will always precede any object. But, at least in Degema, that is as far as head-movement goes (though this need not be true of all SVCs-see Sect. 6). Rolle and Kari (2016) and Rolle (2020) argue that in Degema, the second (lower) verb does not undergo head-movement into the (higher) first verb (see also Baker 1989; Aboh 2009), and we follow their analysis. And following Rolle (2020) once again (at least in part), this structure is subsequently manipulated postsyntactically to copy the Asp node onto both verb complexes, and insert subject agreement $\left(\mathrm{Agr}_{\mathrm{SUBJ}}\right)$ nodes onto both verb complexes-discussed next.

\subsection{Morphology}

We broadly adopt the morphological analysis of Rolle (2020) regarding how aspect enclitics and subject agreement proclitics end up on verbs in an SVC. However, because we do not propose to capture the single- vs. double-marking pattern in the morphological derivation, our morphological analysis is slightly simpler than Rolle's: we claim that by the end of the morphological derivation every verb in an SVC will end up with its own $\mathrm{Agr}_{\text {SUB }}$ node, to be exponed as an agreement proclitic, and (for some aspectual values) its own $\operatorname{Agr}_{\mathrm{ASP}}$ node, to be exponed as an aspect enclitic. So at the end of the morphological derivation, a two-verb SVC will have a structure like (7).

$\left[v \mathrm{P}\left[v \operatorname{Agr}_{\mathrm{SUBJ}}{ }^{0}+v+\mathrm{V}+\operatorname{Agr}_{\mathrm{ASP}}{ }^{0}\right]\right.$ (object) $\left[{ }_{v \mathrm{P}}\left[{ }_{v} \operatorname{Agr}_{\mathrm{SUBJ}}{ }^{0}+v+\mathrm{V}+\operatorname{Agr}_{\mathrm{ASP}}{ }^{0}\right]\right.$ (object) $\left.]\right]$

It's important to note our assumption that much syntactic information, including node labels and constituency relations (like the c-command relation between the $v$ nodes in (7)), is retained throughout the postsyntactic morphological derivation: both mor- 
phological detail and high-level syntactic constituency is accessible at the syntaxprosody interface (on which see Sect. 4.1). ${ }^{1}$

We make use of a serial DM model in which the order of operations is as in (8) (Embick and Noyer 2001). We only include those operations that are necessary for our analysis. There are likely others: for instance Local Dislocation (Embick and Noyer 2001). See Arregi and Nevins (2012) for a more extensive, ordered list of morphological operations.

\section{Dissociated Node Insertion (DNI) > Vocabulary Insertion (VI)}

Following Rolle, we assume that each verb complex (a complex head consisting of $v$ + lexical V) receives an $\mathrm{Agr}_{\mathrm{SUBJ}}$ node and an $\mathrm{Agr}_{\mathrm{ASP}}$ node by DNI. ${ }^{2}$ We will sometimes employ Choi and Harley's (2019) intuitive term '(node) sprouting' to describe DNI. Note that because the $\mathrm{Agr}_{\text {SUBJ }}$ and $\mathrm{Agr}_{\mathrm{ASP}}$ nodes are appended to the verb complex in the morphological derivation, $v$ remains the label of the complex head (this point is relevant for prosodification, in the next section).

We have thus derived a double-marking pattern, which is attested in the event that a heavy object intervenes between the verbs in an SVC, e.g. (5). ${ }^{3}$ However, this leaves unexplained the single-marking pattern, in which multiple verbs and light pronouns in an SVC cluster together, and the whole complex is bookended by a single proclitic and a single enclitic as in (4). Rolle (2020) views this alternation as unexplainable in a serial model of morphology: it requires the morphology to 'know' whether or not a heavy object DP will linearly intervene in the SVC-something which is undetermined at the point of VI-and in response to that, fail to insert the second set of nodes. However, while Rolle's solution to the problem is to abandon serial morphology altogether, we propose an alternative: serial morphology should be maintained, and the single/double-marking alternation should be accounted for at the syntax-prosody interface.

\footnotetext{
${ }^{1}$ We do not take a position on whether the morphological component can be somewhat destructive, and remove some of the syntactic structure. We only note that it cannot be completely destructive, removing all syntactic structure

${ }^{2}$ Rolle proposes that aspect enclitics are in fact the clausal Asp head itself, or a copy of this head. We depart from his analysis for reasons of simplicity, though it would not affect anything if we adopted it.

${ }^{3}$ Rolle (2020:15) and Rolle and Kari (2016:147) describe one context in which the verbs in an SVC can bear different agreement proclitics, shown in (i). Here, the proclitic on the first verb must be Set 2 and the one on the second verb must be Set 1, and they show up regardless of the presence of an intervening heavy object. Furthermore, the aspect enclitic (if present) fails to be copied onto the second verb, and the resulting clause is interpreted idiomatically as having imperfective aspect (habitual or present continuous). We assume that these SVCs must have a somewhat different morphological derivation from typical SVCs, not least because they do not show the single/double-marking alternation discussed here, and together with Rolle (2020) we set them aside.
}

$$
\begin{aligned}
& \text { eni [e- dúw -n ] ộyi [mẹ́- tá ] } \\
& \text { we 1PL.SET2- follow-FAC him/her 1PL.SET1- go } \\
& \text { 'We are going with him.' }
\end{aligned}
$$




\section{Proposal: Parallel prosodification}

Our basic idea is that the single/double-marking alternation emerges when two inviolable constraints come into conflict. On the one hand, adjacent verbs in SVCs must cluster together into a single prosodic word (PWd). This is enforced with a constraint SERIALIZE. On the other hand, there is an absolute ban on repeated inflectional material within the same PWd (Kinyalolo's Constraint, a.k.a. KINYALOLO). When SERIALIZE and KINYALOLO conflict, the only way of satisfying both-the least worst option-is to cluster the adjacent verbs into a single prosodic word, and delete one set of inflectional markers.

In this section we first discuss our basic approach to the syntax-prosody interface, which, unlike the morphological module, we do take to be parallel in nature rather than serial (Sect. 4.1). We then consider obligatory prosodic verb-clustering in Degema SVCs, and how it is enforced at the syntax-prosody mapping by SERIALIZE (Sect. 4.2). Following that, we consider the ban on repeated inflectional material within a single PWd, enforced by KINYALOLO (Sect. 4.3). Finally, we show how these constraints together derive the single/double-marking alternation (Sect. 4.4).

\subsection{The syntax-prosody interface}

We assume that prosodic structure is a level of representation separate from syntactic structure. Prosodic structures are composed of hierarchically-organized constituents bearing prosodic category labels, such as a phonological word (PWd) or phonological phrase (PPh)—see Selkirk (1981), Beckman and Pierrehumbert (1986) and Nespor and Vogel (1986), among others. We further assume that the prosodic structure of a given phrase is built according to the principles of Match Theory (Selkirk 2009, 2011), which falls in the family of indirect reference theories of the syntax-prosody interface. Such theories hold that prosodic structure is the result of a negotiation between several competing pressures, and following Selkirk (1996, 2000, 2009, 2011) and Truckenbrodt (1995, 1999), among others, we model this interaction in Optimality Theory (OT, Prince and Smolensky 1993).

One kind of pressure is for prosodic structure to be isomorphic to syntactic structure. ${ }^{4}$ This pressure is embodied in the Match constraints, which enforce correspondence between syntactic categories and prosodic categories. For the purposes of this paper, we make use only of MATCH WORD, which enforces a mapping between syntactic heads $\left(\mathrm{X}^{0} \mathrm{~s}\right.$, which may have complex internal structure) and PWds. Another kind of pressure is for prosodic structure to satisfy independent well-formedness conditions, which do not make reference to input syntactic structure, embodied by constraints enforcing, among other things, binary-branching (e.g. Ghini 1993; Inkelas and Zec 1995; Elfner 2012), equal weight between prosodic sisters (e.g. Myrberg 2013) and non-recursion (e.g. Selkirk 1996, 2000).

A third kind of pressure is for prosodic structure to satisfy certain prosodic desiderata which make reference to properties of syntactic structure (or at least to the terminal nodes in syntactic structure) other than simple constituency relations. Recent

\footnotetext{
${ }^{4} \mathrm{~A}$ reviewer correctly notes that this is a really a pressure for isomorphism between prosodic structure and morphological structure, given that prosody sees the output of the morphological derivation, rather than the pre-morphological syntactic structure.
} 
examples include constraints enforcing the idiosyncratic prosodic requirements of particular morphemes (e.g. the SUBCAT constraint employed by Bennett et al. 2018 and Tyler 2019), and constraints requiring certain syntactic dependencies to be reflected in prosodic phrasing (e.g. Clemens's ARGUMENT- $\phi$ 2014, 2019, or Henderson's COMPLEMENT- $\phi$ 2012). As Clemens (2019) notes, the idea that selectional relations are projected in some way into prosodic structure is also a key part of Selkirk's (1984) Sense Unit Condition and, more recently, Richards's (2016) notion of Selectional Contiguity.

The crucial constraints in our account of the single/double-marking alternation in Degema-SERIALIZE and KINYALOLO - are both of this latter variety, in that they require reference to syntactic and prosodic structure but are not about enforcing isomorphy between the two. Both constraints are independently motivated in both a typological and theoretical perspective. We provide an overview of these motivations next, noting that the formalization of the first constraint in particular is somewhat overdue.

\subsection{Serialize}

In Sect. 2.2 we saw that single-marking SVCs form a single prosodic unit of some kind, while double-marking SVCs do not have this property. What we would like to highlight is the fact that this kind of clustering is very common in a typological perspective, being essentially the norm for contiguous SVCs (i.e. SVCs where the verbs are not interrupted by other constituents). Consider SVCs in Khwe (Khoisan). Like Degema, Khwe allows both contiguous SVCs, where the verbs are adjacent as in (9a), and non-contiguous SVCs, where the verbs are separated by some intervening (non-inflectional) elements as in (9b).

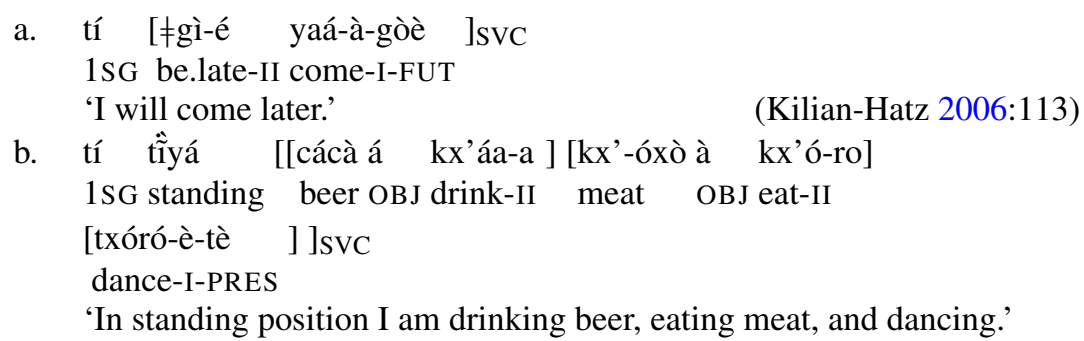

From Kilian-Hatz's description of the prosody of Khwe SVCs, we can determine that the contiguous SVC in (9a) forms a single intonation unit. She states that "the lexical elements of most [SVCs] maintain their internal tone melody, but the first word takes the main stress which is realized as a downdrift on the verbs following the V1 [first verb]" (Kilian-Hatz 2006:121). The non-contiguous SVC in (9b), by contrast, would have to consist of multiple intonation units, as per her generalization that SVCs "do not form such an intonation unit if the verbs have different objects preceding their corresponding verb; in these cases, every verb takes its own stress and the verb phrases may be separated by a short pause" (ibid.). 
As another example of a pattern where clustering is dependent on the verbs being contiguous, Ingram (2006) states, of SVCs in Dumo, that "phonologically, all noncontiguous SVCs consist of verbs that are realized as separate phonological words (where a phonological word is defined by the presence of a single word-level primary stress). Amongst contiguous SVCs, however, SVCs are treated as single phonological words with respect to stress assignment."

In overview articles of SVCs, Aikhenvald (2006:7) states that "a serial verb construction has the intonational properties of a monoverbal clause, and not of a sequence of clauses," and Dixon (2006:339) states than an SVC "is like a single predicate in prosodic properties [...] an SVC generally constitutes one intonation group; and, in most cases, no pause is possible in the middle of an SVC." Haspelmath (2016:308) concludes, "I have not come across any work that contradicts [Aikhenvald's generalization], so I am assuming that this is true of all SVCs." While we take these conclusions to be indicative of the clustering nature of SVCs in the phonology, these impressions were not based on a systematic typological survey. It is also important to acknowledge that these authors are all describing SVCs generally, rather than contiguous SVCs in particular; non-contiguous SVCs seem to be rarer, and the presence of contiguous SVCs in a given language does not imply the presence of noncontiguous SVCs.

Given that phonological clustering seems to be a common property of SVCs crosslinguistically, we tentatively propose that this effect is the result of a high-ranked syntax-prosody interface constraint SERIALIZE, motivated by the prosodic typology of SVCs. ${ }^{5}$ SERIALIZE penalizes output prosodic structures in which $v$ nodes, which are linearly adjacent and in an asymmetric c-command relation in the input, fail to form a single prosodic word. It is defined formally in (10). ${ }^{6}$

\section{SERIALIZE}

Assign one violation for every pair of linearly adjacent $v$ heads, where one asymmetrically c-commands the other, that do not form a single PWd.

SERIALIZE can be thought of as a cousin of Henderson's (2012) COMPLEMENT- $\phi$, which he employs to explain why certain heads form a phonological phrase (' $\phi$ ') with their complement. There are some important differences between SERIALIZE and COMPLEMENT- $\phi$, however. Firstly, they involve different syntactic and prosodic categories: on the syntactic side, SERIALIZE applies only to $v \mathrm{P}$ complements of $\mathrm{V}$, and exempts DP complements; on the prosodic side, SERIALIZE creates prosodic words, rather than phonological phrases. Secondly, SERIALIZE is sensitive to adjacency: a $\mathrm{V}$ that is not adjacent to its complement $v \mathrm{P}$ (as in (6)) is not required by

\footnotetext{
${ }^{5}$ Nicholas Rolle (p.c.) notes an exception to the typological generalization: in SVCs in Kalabari (Ijo), adjacent verbs do not form a prosodic unit, even though other adjacent lexical categories in this language do cluster into a single unit (Harry and Hyman 2014). This pattern is generable in our system through varying the constraint ranking (MATCH WORD $\gg$ SERIALIZE), which highlights the value of encoding serialization as a violable constraint rather than via some more universal mechanism.

${ }^{6}$ The linear adjacency condition in (10) ensures that SERIALIZE does not serialize verbs across intervening heavy objects. The c-command condition ensures that SERIALIZE does not force adjacent verbs in covert coordination structures to serialize, since there is no c-command relation between the $v$ heads associated with the two verbs in a covert coordination structure—see the discussion in Sect. 4.4 and Rolle 2020:Sect. A3.2. We also assume that verbs that are separated by clause boundaries are exempt from SERIALIZE.
} 
SERIALIZE to form a PWd with it. Thirdly, SERIALIZE requires that adjacent heads be prosodified together, while COMPLEMENT- $\phi$ requires that a head be prosodified with its entire complement phrase. Ultimately, SERIALIZE cannot be reduced to a flavor of COMPLEMENT- $\phi$.

In order for SERIALIZE to make its effects felt in the prosodic output, it must outrank MATCH WORD, the constraint responsible for enforcing a one-to-one correspondence between syntactic terminals and PWds (see Selkirk 2011). The tableau in (11) shows how a simple two-verb SVC is realized as a single PWd at the syntaxprosody interface. Note that the $v$ heads will be internally complex-this detail is not shown here.

\begin{tabular}{|c|c|c|c|c|}
\hline \multicolumn{3}{|r|}{$v^{0} v^{0}$} & SERIALIZE & MATCH WORD \\
\hline L安 & a. & {$\left[\begin{array}{ll}v & v]_{\mathrm{PWd}}\end{array}\right.$} & & $* *$ \\
\hline & b. & {$[v]_{\mathrm{PWd}}[v]_{\mathrm{PWd}}$} & $* !$ & \\
\hline
\end{tabular}

The tableau in (12) shows how SERIALIZE has no effect when a two-verb SVC is intervened by a heavy element.

\begin{tabular}{|c|c|c|c|}
\hline \multicolumn{2}{|r|}{$v^{0} \mathrm{~N}^{0} v^{0}$} & SERIALIZE & MATCH WORD \\
\hline ar $\mathrm{a}$. & {$[v]_{\mathrm{PWd}}[\mathrm{N}]_{\mathrm{PWd}}[v]_{\mathrm{PWd}}$} & & \\
\hline $\mathrm{b}$. & {$[v \mathrm{~N} v]_{\mathrm{PWd}}$} & & $* ! * *$ \\
\hline
\end{tabular}

We do not deny that SERIALIZE is essentially a simple formalization of a descriptive statement like 'adjacent verbs in SVCs cluster into prosodic units.' One might wonder if this prosodic property of SVCs could be derived from their morphosyntactic properties without reference to a specialized constraint, but it is not obvious how this idea would work. One cannot appeal to syntactic constituency, since verbs in SVCs are not generally considered to form a syntactic constituent (see Sect. 3.1). Nor can one appeal to (purely) prosodic well-formedness constraints, since prosodic clustering in SVCs requires reference to the syntactic category $\mathrm{V}$, and does not apply to, for instance, Ns. Whether SERIALIZE can be deconstructed or derived is a question which we hope additional work can answer (see also the discussion in Sect. 6).

We also do not deny that the formalization of SERIALIZE given in (10) is tied to one particular syntactic analysis of SVCs - the 'nested vPs' analysis of Collins (2002), which is adopted by Rolle (2020) (see Sect. 3.1). However, the basic idea is translatable between different analyses: there is a special constraint which, upon identifying adjacent verbs in the syntactic configuration that is characteristic of SVCs, is only satisfied when these verbs are mapped to a single prosodic word in the output.

We now move on to the second syntax-prosody interface constraint necessary to derive the Degema pattern.

\subsection{Kinyalolo's Constraint}

We propose that there is a highly-ranked constraint active in Degema which bans repeated inflectional morphemes within a single prosodic word. This has been termed Kinyalolo's Constraint in much previous work (see Kinyalolo 1992; Carstens 2003, 
2005; Henderson 2011; Baker 2010, 2012; Baker and Kramer 2018; Alok and Baker 2018; see also an informal proposal by Hale et al. 1991:267).

Kinyalolo's Constraint is motivated by the existence of patterns like those in (13), from KiLega. Here, the number of overt agreement morphemes in a clause tracks the number of verb(-like) words, with each verb(-like) word having one and only one subject agreement morpheme.

a. Mikoko z-á-bézág-á zí-se

4.sheep 4.AGR-A-be-FV 4.AGR-about.to

z-á-sínz-u-a.

4.AGR-ASP2-slaughter-PASS-FV

'Sheep were about to be slaughtered.'

b. Masungá má-kilí m-á-yik-u-á.

6.yam 6.AGR-be.still 6.AGR-ASP2-cook-PASS-FV

'The yams are still being cooked.'

c. pro Mú-ná-kúbul-íl-é mázi.

IIPL.AGR-MOD-pour-ASP-FV 6.water

'You could have poured water.'

(KiLega, Carstens 2005:253-5)

Carstens (2005), following a pioneering analysis by Kinyalolo (1992), argues that multiple heads within the functional spine of a KiLega clause agree with the subject (e.g. T, Asp1, Mod, Asp2 and others). In her analysis, when the functional spine is realized as several different phonological words, as in (13a), then the agreement morphemes mostly show up unhindered. But when the functional spine of a clause is realized as fewer phonological words, as in (13b), or just a single word as in (13c), all but the outermost subject-agreement morphemes are 'suppressed' by Kinyalolo's Constraint. Alok and Baker (2018) provide the definition in (14).

\section{Kinyalolo's Constraint (Alok and Baker 2018:(21))}

In a word (phonologically defined), AGR on one head is silent if and only if its features are predictable from AGR on another head.

The fact that (14) makes reference to both a prosodic category (PWd) and a (morpho)syntactic category (AGR) means that it can only apply at the syntax-prosody interface. It cannot apply straightforwardly to an un-phonologized morphological representation, nor can it be applied to a post-morphosyntactic phonological representation.

Degema clearly adheres to Kinyalolo's Constraint. When verbs in an SVC are clustered into a single PWd, there is a single agreement proclitic and a single aspect enclitic for the entire PWd (i.e. single-marking). When verbs in an SVC form separate PWds, each verb has its own agreement proclitic and aspect enclitic (i.e. doublemarking).

To enforce Kinyalolo's Constraint in Degema, we adopt the spirit of (14), although it requires some adaptation for use in an OT framework. As currently stated, it contains both a 'constraint' (no word-internal repetition of AGR morphemes) and its 
repair (delete an AGR morpheme). Only the true 'constraint' part can be encoded as an OT constraint: KINYALOLO is defined in (15).

\section{KINYALOLO}

Assign one violation for every pair of featurally-identical Agr nodes within the same PWd.

In order to allow deletion of redundant word-internal AGR nodes (in Degema, these are $\operatorname{Agr}_{\text {SUBJ }}{ }^{0}$ and $\operatorname{Agr}_{\mathrm{ASP}}{ }^{0}$ nodes inserted on $v$ heads), KINYALOLO must outrank whatever faithfulness constraint or constraints enforces the realization of these nodes in the output-we employ a constraint MAX(AGR). The effect of the KINYALOLO $\gg \operatorname{MAX}(\mathrm{AGR})$ ranking is illustrated in the tableau in (16). ${ }^{7}$

\begin{tabular}{|cc||c|c|}
\hline & {$\left[\mathbf{X}^{0} \ldots \operatorname{Agr}_{[\mathbf{i}]} \ldots \operatorname{Agr}_{[\mathrm{i}]} \ldots\right]$} & KINYALOLO & MAX(AGR) \\
\hline \hline a. & {$\left[\ldots \operatorname{Agr}_{[\mathrm{i}]} \ldots\right]_{\operatorname{PWd}}$} & & $*$ \\
\hline b. $\quad\left[\ldots \operatorname{Agr}_{[\mathrm{i}]} \ldots \operatorname{Agr}_{[\mathrm{i}]} \ldots\right]_{\mathrm{PWd}}$ & $* !$ & \\
\hline
\end{tabular}

In sum, we have seen that in Degema SVCs, adjacent verbs and light object pronouns always form a single PWd (Sect. 4.2), and in this section we have also seen that Kinyalolo's Constraint is scrupulously obeyed. We propose that these two inviolable syntax-prosody mapping constraints derive the single- vs. double-marking patterns in Degema, without recourse to parallel computation in the morphology.

\subsection{Deriving single vs. double-marking at the syntax-prosody interface}

SERIALIZE forces adjacent $v$ 's to cluster into a single PWd, and KINYALOLO bars PWd-internal repeated functional material. Together, these will allow us to derive the distribution of the single- vs. double-marking alternation in Degema SVCs.

The basic idea is that both constraints are inviolable, but by creating the large, multiple- $v$-spanning PWds necessitated by SERIALIZE, the resulting PWds will often contain multiple identical inflectional morphemes (agreement proclitics and aspect enclitics). If these were represented in the phonological output, the result would violate KINYALOLO, so in order to keep both constraints satisfied, all but one PWdinternal instance of each clitic goes unrealized.

The tableau in (17) illustrates an input that leads to a single-marking output. Because nothing intervenes between the two $v$ 's, SERIALIZE forces them into a single PWd, and KINYALOLO necessitates the deletion of redundant PWd-internal morphology.

\begin{tabular}{|c|c|c|c|c|c|}
\hline & {$\left[v \operatorname{Agr}_{\mathrm{SUBJ}}-\mathrm{V}-\mathbf{A g r}_{\mathrm{ASP}}\right]\left[v \operatorname{Agr}_{\mathrm{SUBJ}}-\mathrm{V}-\mathrm{Agr}_{\mathrm{ASP}}\right]$} & KINYALOLO & SERIALize & $\operatorname{MAX}(\mathrm{AGR})$ & MATCH WORD \\
\hline $\cos$ & {$\left[\mathrm{Agr}_{\mathrm{SUBJ}}-\mathrm{V} \text { V-Agr }{ }_{\mathrm{ASP}}\right]_{\mathrm{PWd}}$} & & i & $* *$ & $* \ldots$ \\
\hline & {$\left[\mathrm{Agr}_{\mathrm{SUBJ}}-\mathrm{V}-\mathrm{Agr}_{\mathrm{ASP}}\right]_{\mathrm{PWd}}\left[\mathrm{Agr}_{\mathrm{SUBJ}}-\mathrm{V}-\mathrm{Agr}_{\mathrm{ASP}}\right]_{\mathrm{PWd}}$} & & $* !$ & & 1 \\
\hline & {$\left[\mathrm{Agr}_{\mathrm{SUBJ}}-\mathrm{V}-\mathrm{Agr}_{\mathrm{ASP}} \mathrm{Agr}_{\mathrm{SUBJ}}-\mathrm{V}-\mathrm{Agr}_{\mathrm{ASP}}\right]_{\mathrm{PWd}}$} & $* !$ & 1 & & $* \ldots$ \\
\hline
\end{tabular}

\footnotetext{
${ }^{7}$ As with SERIALIZE, KINYALOLO may be ranked differently in different languages, with the result that some languages will select outputs that are not compliant with KINYALOLO. Indeed, many attested instances of PWd-internal multiple exponence would be in violation of Kinyalolo's constraint. We view this as a strength of our proposal, in that it allows for greater typological coverage than previous analyses, where Kinyalolo's Generalization is an inviolable PF filter of uncertain cross-linguistic status.
} 
When there is intervening material, SERIALIZE does not demand that the $v$ 's in an SVC form a single PWd, because they are not adjacent. This is shown in (18).

\begin{tabular}{|c|c|c|c|c|c|c|}
\hline & & {$\left[{ }_{v} \mathbf{A g r}_{\mathrm{SUBJ}_{\mathrm{J}}}-\mathrm{V}-\mathbf{A g r}_{\mathrm{ASP}}\right] \mathbf{N}\left[{ }_{v} \mathbf{A g r}_{\mathrm{SUBJ}}-\mathrm{V}-\mathrm{Agr}_{\mathrm{ASP}}\right]$} & KINYALOLO & SERIALIZE & MAX(AGR) & MATCH WORD \\
\hline 卌 & a. & {$\left[\mathrm{Agr}_{\mathrm{SUB}} \mathrm{J}-\mathrm{V}-\mathrm{Agr}_{\mathrm{ASP}}\right]_{\mathrm{PWd}}[\mathrm{N}]_{\mathrm{PWd}}\left[\mathrm{Agr}_{\mathrm{SUBJ}}-\mathrm{V}-\mathrm{Agr}_{\mathrm{ASP}}\right]_{\mathrm{PWd}}$} & & $i$ & & i \\
\hline & b. & {$\left[\mathrm{Agr}_{\mathrm{SUBS}}-\mathrm{V} N \mathrm{~N} \text { V-Agr }{ }_{A S P}\right]_{P W d}$} & & 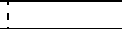 & *!* & *... \\
\hline & c. & {$\left[\mathrm{Agr}_{\mathrm{SUBJ}}-\mathrm{V}-\mathrm{Agr}_{\mathrm{ASP}} \mathrm{N} \mathrm{Agr}_{\mathrm{SUBJ}}-\mathrm{V}-\mathrm{Agr}_{\mathrm{ASP}}\right]_{\mathrm{PWd}}$} & $* !$ & it & & *... \\
\hline
\end{tabular}

Before moving on to our evaluation of Rolle's 'OT-DM' analysis of the Degema pattern, we compare our account to a similar account that Rolle considers and rejects, and we address two outstanding questions relating to our analysis.

In the analysis rejected by Rolle (2020:Sect. A3.2), the single-marking pattern is a consequence of redundant clitics being deleted under identity with the clitics on an adjacent verb. This is somewhat like our analysis, in that KINYALOLO is a kind of anti-identity constraint. The key difference between the analysis Rolle rejects and our analysis is that KINYALOLO is sensitive only to identity with the prosodic word, while in Rolle's deletion-under-identity account, there is no reference to prosodic wordhood, only to adjacency. Accordingly, Rolle argues against the deletion-underidentity account by showing that a single-marking pattern does not emerge in a covert VP coordination structure, even though, in such structures, two inflected verbs may end up adjacent to one another. However, in our account, we would not expect two verbs in a covert coordination structure to form a single prosodic word (because SERIALIZE would not apply to a covert coordination structure), and so we would not expect them to be within the purview of KINYALOLO. Thus Rolle's argument against a deletion-under-identity account does not generalize to our account.

The two outstanding questions relating to our analysis are addressed in the following sections. Firstly (Sect. 4.4.1): when deriving the double-marking pattern, why is it the outermost clitics that are retained, with the inner clitics being deleted? Why not delete the outermost clitics and retain the inner ones? Secondly (Sect. 4.4.2): what happens to the light object pronouns, which show up internally to the SVC?

\subsubsection{Retaining the outermost clitics}

Here we sketch an account of why it is the leftmost proclitic and the rightmost enclitic that survive in a single-marked SVC, rather than SVC-medial proclitics and enclitics. Our account relies crucially on the notion that Vocabulary Items may be pre-specified to integrate into prosodic structures in particular ways (Inkelas 1989; Inkelas and Zec 1990; Bennett et al. 2018; Zec 2005; Tyler 2019). The intuition is essentially that proclitics are pre-specified to sit at the left edge of a PWd and that enclitics are pre-specified to sit at the right edge of a prosodic word. Therefore by retaining the outermost clitics, the clitics' prosodic pre-specifications are most easily satisfied. By contrast if SVC-medial clitics were retained instead, either they would have to simply sit in the middle of the SVC-spanning PWd, violating their prosodic pre-specification, or some complex PWd-within-PWd structure would have to be constructed. Both options are less optimal than simply retaining the outer clitics rather than the inner clitics. 
For reasons of space we do not provide the explicit implementation. Following Bennett et al. (2018) and Tyler (2019), we simply assume that the agreement clitics have prosodic subcategorization frames, which are enforced at the syntax-prosody interface by an inviolable constraint SUBCAT. We do not claim that this is the only theoretical option that would account for why the outer clitics are retained in singlemarking environments rather than SVC-internal clitics. We simply claim that it is one plausible option. ${ }^{8}$ Rolle (2020) achieves a similar goal using ALIGN constraints.

\subsubsection{Light object pronouns}

Monosyllabic object pronouns in Degema always show up internally to the verb/SVC complex. When there is just one verb, the light object pronoun will appear between the verb stem and the aspect enclitic, as in (19a). With an SVC, it may show up between the verb and the final aspect enclitic, as in (19b) or between two SVC-internal verbs, as in (19c) - this depends on whether it is the object of the first or second verb (see Kari 2003).
a. [o- kótú wọ́ -ōn ]
3SG.SET2- call you -FAC
'He/she called you.'
b. Breno [o- sóm fíyé wọ́ -ōn ]
Breno 3SG.SET2- be.good be.more.than you -FAC
'Breno is handsomer than you.'
Breno 3SG.SET2- follow me go-FAC
'Breno went with me.'
c. Breno [o- dúw mé tá -ān ]

(Kari 2003:281)

Rolle (2020) proposes that light object pronouns incorporate into the verb constituent by a process of Local Dislocation (LD). This accounts for both the fact that they precede the aspect enclitic and the fact that they do not induce the double-marking pattern. We broadly follow this part of his analysis, in that we assume that light object pronouns incorporate into the $v+\mathrm{V}$ complex head that selects them.

However, we do not take a view on whether this incorporation is morphological (i.e. lexically-arbitrary, via LD) or prosodic (driven by interface considerations, cf. Bennett et al. 2016), since it would not make a difference for our analysis. If morphological, then pronoun incorporation moves a pronoun inside a complex $v$ node, rendering it irrelevant for the computation of the single vs. double-marking pattern. If prosodic, then pronoun incorporation is calculated in parallel with the computation of single- vs. double-marking, but does not affect it. Our more substantive disagreements with OT-DM are discussed next.

\footnotetext{
${ }^{8}$ It is notable that, to our knowledge, in all previous instances in which Kinyalolo's Constraint has been invoked, the surviving AGR morpheme is at the edge of the prosodic/morphological word (e.g. (13c)).
} 


\section{Against OT-DM}

Rolle proposes an analysis in which the difference between single and double marking in Degema SVCs is the result of an 'anti-clitic' conspiracy. The basic idea is that sprouting clitics is costly, and should be avoided wherever possible. The serialization that adjacent verbs undergo in SVCs is a conspiracy to reduce the number of clitics that need to be sprouted-once serialized, the two verbs are treated as a single verb, and only one pair of clitics needs to be sprouted. In this section, we describe a simplified version of Rolle's analysis, and discuss some issues it presents.

\subsection{Assumptions}

As mentioned earlier, OT-DM assumes that the traditional serially-ordered operations of DM can apply freely and in parallel, and OT constraints evaluate the output. For Rolle's purposes, the most relevant operation is DNI. The constraint DEP-AGR in (20) is at the core of Rolle's analysis: it penalizes DNI of Agr $_{\text {SUBJ }}$ and Agr $_{\text {ASP }}$ nodes. ${ }^{9}$

\section{DEP-AGR}

Assign one violation for every $\operatorname{Agr}_{\text {SUBJ }}$ and $\operatorname{Agr}_{\mathrm{ASP}}$ that is inserted.

Rolle also assumes that the output of the morphological module consists of morphological words (MWds) bearing a category label. The determination of an MWd's category label is similarly regulated by OT constraints, which look at the syntactic category labels of the terminals inside the MWds. The constraint LABEL-MWD in (21) basically ensures that syntactic terminals within an MWd 'project' their category label onto the MWd they are contained within. ${ }^{10}$ So a verb and $v$ want to be inside an MWd with the label $\{\mathrm{V}\}$, whereas a noun and D want to be inside an MWd with the label $\{\mathrm{D}\}$.

\section{LABEL-MWD}

Assign one violation for every $\mathrm{V}$ or $\mathrm{D}$ within an $\mathrm{MWd}$ that does not share its category label.

Although Rolle does distinguish MWds from PWds, they always correspond in his outputs (thanks to a highly-ranked constraint $\mathrm{MWD}=\mathrm{PRWD}$ ), so $\mathrm{MWd}$ and $\mathrm{PWd}$ can be viewed as interchangeable categories in this section.

Finally, there are constraints which make reference both to DM operations and to MWds. The constraint V(AGR) forces every MWd with the label $\{\mathrm{V}\}$ to be marked with both an agreement proclitic and an aspect enclitic. ${ }^{11}$

$\underline{\mathrm{V}(\mathrm{AGR})}$

Assign one violation for every MWd with the label $\{\mathrm{V}\}$ which is not marked with an $\mathrm{Agr}_{\text {SUBJ }}$ node and $\mathrm{Agr}_{\mathrm{ASP}}$ node.

\footnotetext{
${ }^{9}$ DEP-AGR is in fact an amalgam of three of Rolle's constraints: DEP-IO(NODE), *AGR ${ }_{\text {ASP }}$ and *AGR ${ }_{\text {SBJ }}$.

${ }^{10}$ LABEL-MWD amalgamates Rolle's MWD $\{$ LABEL $\}$ and MAP(WD_TYPE). Rolle also prevents an MWd from bearing multiple category labels with a constraint *COMPLEXMWD $\{$ LABEL $\}$.

${ }^{11} \mathrm{~V}(\mathrm{AGR})$ is an amalgam of two of Rolle's constraints: V=WF_MWD(AGR $\mathrm{SBJ}$ ) and $\mathrm{V}=\mathrm{WF} \_\mathrm{MWD}(\mathrm{ASP})$.
} 
V(AGR) and LABEL-MWD outrank DEP-AGR. With these preliminaries in place, we can derive the single and double-marking patterns in Degema SVC.

Note that in order to account for the behavior of light object pronouns (see Sect. 4.4.2), Rolle adds two components to his analysis: firstly, he fine-tunes the MWdlabeling mechanism, such that it only cares about projecting the label of prosodicallystrong D-labelled syntactic terminals; secondly, he includes some constraints that force the light pronoun to be incorporated into an adjacent MWd. Since these are orthogonal to the main distinction between single-marking and double-marking in SVCs, we omit them from the short discussion here.

\subsection{Derivations}

The most relevant candidates are repeated in each of the examples below; see the original paper for full tableaux and a thorough discussion of possible candidates and combinatorial typologies.

The derivation of morphological marking on a single verb, with a full DP object, is shown in (23). Candidate (a), in which no Agr nodes are inserted, induces a fatal violation of $\mathrm{V}(\mathrm{AGR})$, and candidate (c), in which the object DP forms part of the same MWd as V, induces a fatal violation of LABEL-MWD. As a result, the DP is not "incorporated" into a single verb but appears after the verb and its clitics (23b).

\begin{tabular}{|c|c|c|c|c|c|}
\hline \multicolumn{3}{|r|}{$v+$ V DP } & \multirow[t]{2}{*}{ LABEL-MWD } & \multirow{2}{*}{$\frac{\mathrm{V}(\mathrm{AGR})}{* 1}$} & \multirow[t]{2}{*}{ DEP-AGR } \\
\hline & a. & $(\mathrm{V})_{\{\mathrm{V}\}}(\mathrm{DP})_{\{\mathrm{D}\}}$ & & & \\
\hline 证果 & b. & $\left(\mathrm{Agr}_{\mathrm{SBJ}}-\mathrm{V}-\mathrm{AGR}_{\mathrm{ASP}}\right)_{\{\mathrm{V}\}}(\mathrm{DP})_{\{\mathrm{D}\}}$ & & & $*$ \\
\hline & c. & $\left(\mathrm{AGR}_{\mathrm{SBJ}}-\mathrm{V}-\mathrm{DP}-\mathrm{AGR}_{\mathrm{ASP}}\right)_{\{\mathrm{V}\}}$ & $* !$ & & $*$ \\
\hline
\end{tabular}

Turning to serial verb constructions, we can now see why single-marking emerges in the absence of an intervening object DP. The fact that that the two verbs in an SVC share a category label means that they can both sit inside the same MWD without inducing a violation of LABEL-MWD. Then, the winner is the candidate with fewer violations of DEP-AGR (the anti-clitic constraint):

\begin{tabular}{|cl||c:c|c|}
\hline & {$\left[v_{\mathbf{1}}+\mathbf{V}_{\mathbf{1}}\left[\boldsymbol{v}_{\mathbf{2}}+\mathbf{V}_{\mathbf{2}}\right]\right]$} & LABEL-MWD & $\mathrm{V}(\mathrm{AGR})$ & DEP-AGR \\
\hline \hline a. & $(\mathrm{V} 1)_{\{\mathrm{V}\}}(\mathrm{V} 2)_{\{\mathrm{V}\}}$ & & $* ! *$ & \\
\hline b. $\left(\mathrm{AGR}_{\mathrm{SBJ}}-\mathrm{V} 1-\mathrm{AGR}_{\mathrm{ASP}}\right)_{\{\mathrm{V}\}}\left(\mathrm{AGR}_{\mathrm{SBJ}}-\mathrm{V} 2-\mathrm{AGR}_{\mathrm{ASP}}\right)_{\{\mathrm{V}\}}$ & & $* * ! *$ \\
\hline c. & $\left(\mathrm{AGR}_{\mathrm{SBJ}}-\mathrm{V} 1-\mathrm{V} 2-\mathrm{AGR}_{\mathrm{ASP}}\right)_{\{\mathrm{V}\}}$ & & $*$ \\
\hline
\end{tabular}

Finally, we see why single-marking is unavailable when there is an intervening object DP, and double-marking appears instead. The object prevents the two verbs from forming a single MWd-candidate (25b) contains an unlabelable $\mathrm{MWd}$ - and so the only option is to form two separate MWds, each with their own set of clitics.

\begin{tabular}{|c|c|c|c|c|c|}
\hline \multicolumn{3}{|r|}{$\left[v_{1}+\mathrm{V}_{1}\left[\mathrm{DP}\left[v_{2}+\mathrm{V}_{2}\right]\right]\right]$} & LABEL-MWD & V(AGR) & DEP-AGR \\
\hline 嚓 & a. & $\left(\mathrm{AGR}_{\mathrm{SBJ}}-\mathrm{V} 1-\mathrm{AGR}_{\mathrm{ASP}}\right)_{\{\mathrm{V}\}}(\mathrm{DP})_{\{\mathrm{D}\}}\left(\mathrm{AGR}_{\mathrm{SBJ}}-\mathrm{V} 1-\mathrm{AGR}_{\mathrm{ASP}}\right)_{\{\mathrm{V}\}}$ & & & $* * *$ \\
\hline & b. & $\left(\mathrm{AGR}_{\mathrm{SBJ}}-\mathrm{V} 1-\mathrm{DP}-\mathrm{V} 2-\mathrm{AGR}_{\mathrm{ASP}}\right)_{\{\mathrm{V}\}}$ & $* !$ & & $*$ \\
\hline
\end{tabular}




\subsection{Discussion}

The main contribution of the OT-DM account, as applied to Degema, is to cast the single/double-marking distinction as part of a conspiracy to reduce multiple exponence of clitics. Single-marking is preferred because each clitic is exponed only once. But for this to happen, adjacent verbs in an SVC need to be corralled into a single 'morphological word' (MWd), with each MWd serving as a host for a procliticenclitic pair. Double-marking arises when no single MWd can be formed from the verbs in the SVC (because of the intervening DP), thus forcing two distinct MWds to be formed, each of which then carries its own proclitic-enclitic pair. The distinction between light and heavy intervening material is encoded extrinsically to the constraints, just as in our account.

Rolle (2020) is careful to rule out possible candidates in the individual derivations. Empirically, his proposal seems sound. Our objection to it rests on a number of conceptual considerations. We take issue with (i) prosodic verb-clustering being dependent on a conspiracy to reduce multiple exponence of agreement morphemes, and (ii) the labeling mechanism necessary to match up prosodic words with morphological words, before concluding with general remarks on parallel computation.

First, the account of verb-clustering in SVCs is parochial: as we have discussed, many if not most SVCs, cross-linguistically, occur in the absence of agreement or clitics (Aikhenvald and Dixon 2006). The typological literature indicates that in languages with "contiguous" SVCs (SVCs with no or minimal material permitted to intervene between the verbs), the SVC will very frequently form a single prosodic unit. So if verbs may cluster together in SVCs regardless of agreement marking, an "anti-clitic" conspiracy such as that of OT-DM cannot be a general explanation for clustering. Rather, the theory needs to independently allow verbs to cluster together; we have proposed one way of integrating this phenomenon into our formal theories, using SERIALIZE. Degema is of particular interest because the light/heavy distinction poses an added complication, but this question can be treated separately from the general question of clustering. Likewise the interaction between clustering and agreement, and the interaction between agreement and the prosodic weight of pronouns, are important questions, but again they do not bear directly on the clustering mechanism itself. Our serial analysis, in which morphology feeds prosody but not vice versa, is therefore maximally general as it captures all SVCs including the Degema data, rather than being tailored to the particulars of a single language.

It's worth adding that the OT-DM account also relies on a stipulation that singlemarking in an SVC is the default and double-marking the exception. However, our (equally-stipulated) assumption that each verb in an SVC sprouts its own Agr nodes, which may be deleted during prosodification, shows how an alternative starting assumption leads to an equally viable analysis, but undermines the motivation behind the "anti-clitic" conspiracy. ${ }^{12}$

\footnotetext{
${ }^{12}$ It might be possible to maintain an "insertion" analysis within the general approach presented here. One would first need to assume that in the output of the morphology, there is just one $\mathrm{Agr}_{\mathrm{SUBJ}}$ node and just one $\mathrm{Agr}_{\mathrm{ASP}}$ node per clause. One would also need to reinterpret Kinyalolo's Constraint as enforcing, at the syntax-prosody interface, a one-to-one correspondence between agreement morphemes and prosodic constituents which are capable of bearing agreement. Then, as a result of this reimagined version
} 
Second, the OT-DM account requires morphological words as representations distinct from prosodic words and syntactic heads, as well as an associated mechanism for labeling them. While the notion of a morphological word is not new, recent work indicates that it does not seem to contribute much to Distributed Morphology - the theory in which both Rolle's and our analyses are couched-beyond the existing notion of the complex $X^{0}$ head (Bobaljik and Harley 2017; Choi and Harley 2019) or perhaps certain morphological operations (Embick and Noyer 2001). Within Rolle's account, morphological words serve the single purpose of preventing verbs from prosodically clustering with nouns. This is something our own account encodes using a dedicated (but independently-motivated) syntax-prosody interface constraint SERIALIZE, but we do not require an additional level of postsyntactic representation, with attendant machinery.

More generally, it has been suggested in various ways (from Pullum and Zwicky 1986 to Embick 2010) that morphosyntax and phonology are calculated separately. Embick (2010) in particular defends this kind of view against OT accounts which interleave morphology and phonology, or rank phonology over morphology; see McCarthy (2008) and Wolf (2008) for a few such theories, and Kalin (2018) and Kastner (2019) for rebuttals in additional domains. Rolle employs the traditional assumption that there is a separate component, downstream from the morphology-prosody module, in which regular phonology applies (Rolle 2020:244), so while his account is not a total unification of morphology and phonology_rather a unification of morphology and part of the phonology (prosodification) - its main conceptual drawback is the same as that identified in the works cited above: arbitrary and unconstrained interactions. Within the OT-DM architecture, we might expect to find interactions such as a distinction between single marking and double marking which depends on an arbitrary morphosyntactic feature, for example single marking on singular NPs and double marking on plural NPs. This constraint is easy to encode: 'PWD $=$ PLURAL', on a par with 'MWD=PRWD' mentioned earlier in the context of (21). But if morphosyntax is dissociated from prosody, this kind of constraint no longer fits naturally in the architecture. ${ }^{13}$

\section{Conclusion}

This brief contribution had two goals: to argue against a unified and parallel morphology-prosody component in the grammatical architecture, and to make the

of Kinyalolo's Constraint, an additional pair of agreement nodes would be inserted on each prosodicallyindependent verb. This analysis is very conceptually similiar to Rolle's, but it also strikes us as extremely inelegant: it requires that the syntax-prosody interface be given essentially the same power to insert exponents as the morphological component itself (Rolle doesn't have this problem, since he unifies morphology and prosodification within a single module). By contrast, our analysis requires only that the syntax-prosody interface have the power to delete nodes. However, regardless of the details, it, like our analysis, does not require the parallel computation that Rolle's analysis requires.

${ }^{13}$ Granted, SERIALIZE could also be written so as only to apply to plural nouns, but the way we envision it does not deal with specific features or feature values: it simply combines two syntactic objects of category v. The claim we wish to advance is that SVCs seem to form a robust cross-linguistic phenomenon, and so are worthy of their own constraint, while leaving open the possibility that future work will be able to derive this constraint from independent principles. 
case for a formal implementation of prosodic clustering in serial verb constructions (SERIALIZE). In order to understand the Degema patterns, we have proposed what could be seen as a cross-modular Duke of York effect: clitics are inserted in one module and removed in the next. We discuss some implications for the study of SVCs before concluding.

The view outlined here, with its reliance on SERIALIZE, allows us to take a step back and consider the diversity of SVCs. "Prosodic serialization" may not be a uniform phenomenon. While SERIALIZE is necessary for the analysis of Degema, prosodic serialization in other languages may be the result of syntactic head movement. In $\neq$ Hoan (Collins 2002), verbs in an SVC syntactically incorporate into a single complex head. Their prosodic constituency then follows, by MATCH WORD or something like it, from their syntactic constituency (a point also made in Rolle and Kari 2016:155), and SERIALIZE need not be invoked.

Serial verb constructions in other languages may have a different syntactic structure from that employed here-see, for instance, the VP-to-VP adjunction analysis of Déchaine (1993) and Veenstra (1996). With such a structure, prosodic serialization would not automatically follow from either syntactic constituency or SERIALIZE (at least as it is written here). We see this as suggestive of the idea that SERIALIZE needs to be broken down into its constituent parts. If a language forms SVCs via adjunction rather than complementation, then the c-command condition in our definition of SERIALIZE (in (10)) needs to be separated from the adjacency condition.

Further evidence that a decomposition of SERIALIZE is merited comes from the fact that the adjacency condition on prosodic serialization is not cross-linguistically uniform either. In Saramaccan, all verbs in an SVC show a characteristic tone sandhi rule, regardless of whether or not the verbs in the SVC are separated by an intervening object (Veenstra and Muysken 2017). If SERIALIZE is responsible for prosodically clustering the verbs in a Saramaccan SVC such that the sandhi rule applies, then SERIALIZE, in that language, must be indifferent to linear adjacency. ${ }^{14}$ Other recent work has focused on additional syntactic and semantic issues in SVCs (Zimmermann and Amaechi 2018; Hopperdietzel 2020); we hope that the current work can contribute towards a formal typology of SVCs.

While we have argued against the OT-DM architecture in general and its application to Degema in particular, we hope that it is clear how our own proposal can be falsified: what one would need to show is that verb clustering is a conspiracy, rather than the outcome of a single constraint. In fact, we hope this paper will serve as impetus to further study SERIALIZE and KINYALOLO, be it as holistic constraints or interactions between other constraints. Rolle (2020) showed what such an undertaking could look like. We contended here that his findings actually make the case not for a parallelist OT-DM model but for the ongoing study of serialization and deletion.

Acknowledgements We thank Maria Gouskova, Nicholas Rolle, Coppe van Urk, Hannah Sande, the Georgetown morphology reading group, and three anonymous reviewers. We are also grateful to NYU's MorphBeer reading group for helpful discussion.

Publisher's Note Springer Nature remains neutral with regard to jurisdictional claims in published maps and institutional affiliations.

${ }^{14}$ We thank an anonymous reviewer for bringing the Saramaccan facts to our attention. 
Open Access This article is licensed under a Creative Commons Attribution 4.0 International License, which permits use, sharing, adaptation, distribution and reproduction in any medium or format, as long as you give appropriate credit to the original author(s) and the source, provide a link to the Creative Commons licence, and indicate if changes were made. The images or other third party material in this article are included in the article's Creative Commons licence, unless indicated otherwise in a credit line to the material. If material is not included in the article's Creative Commons licence and your intended use is not permitted by statutory regulation or exceeds the permitted use, you will need to obtain permission directly from the copyright holder. To view a copy of this licence, visit http://creativecommons.org/licenses/by/4.0/.

\section{References}

Aboh, Enoch Oladé. 2009. Clause structure and verb series. Linguistic Inquiry 40(1): 1-33.

Aikhenvald, Alexandra Y. 2006. Serial verb constructions in typological perspective. In Serial verb constructions: A cross-linguistic typology, eds. Alexandra Y. Aikhenvald and Robert M. W. Dixon, 1-68. Oxford: Oxford University Press.

Aikhenvald, Alexandra Y., and Robert M. W. Dixon, eds. 2006. Serial verb constructions: A crosslinguistic typology. Oxford: Oxford University Press.

Alok, Deepak, and Mark C. Baker. 2018. On the mechanics (syntax) of indexical shift: Evidence from allocutive agreement in Magahi. Ms., Rutgers University.

Arregi, Karlos, and Andrew Nevins. 2012. Morphotactics: Basque auxiliaries and the structure of spellout. Dordrecht: Springer.

Baker, Mark C. 1989. Object sharing and projection in serial verb constructions. Linguistic Inquiry 20(4): 513-553.

Baker, Mark C. 2010. On parameters of agreement in Austronesian languages. In Austronesian and theoretical linguistics, eds. Raphael Mercado, Eric Potsdam, and Lisa Travis, 345-374. Amsterdam: John Benjamins.

Baker, Mark. 2012. "Obliqueness" as a component of argument structure in Amharic. In The end of argument structure?, eds. María Cristina Cuervo and Yves Roberge, 43-74. Bengley: Emerald Press.

Baker, Mark, and Ruth Kramer. 2018. Doubled clitics are pronouns: Amharic objects (and beyond). Natural Language and Linguistic Theory 36: 1035-1088.

Beckman, Mary, and Janet Pierrehumbert. 1986. Intonational structure in English and Japanese. Phonology 3: 255-309.

Bennett, Ryan, Emily Elfner, and James McCloskey. 2016. Lightest to the right: An apparently anomalous displacement in Irish. Linguistic Inquiry 47(2): 169-234.

Bennett, Ryan, Boris Harizanov, and Robert Henderson. 2018. Prosodic smothering in Macedonian and Kaqchikel. Linguistic Inquiry 49: 195-246.

Bobaljik, Jonathan David, and Heidi Harley. 2017. Suppletion is local: Evidence from Hiaki. In The structure of words at the interfaces, eds. Heather Newell, Máire Noonan, and Lisa Travis, 141-159. Oxford: Oxford University Press.

Carstens, Vicki. 2003. Rethinking complementizer agreement: Agree with a case-checked goal. Linguistic Inquiry 34(3): 393-412. https://doi.org/10.1162/002438903322247533.

Carstens, Vicki. 2005. Agree and EPP in Bantu. Natural Language \& Linguistic Theory 23(2): 219-279.

Choi, Jaehoon, and Heidi Harley. 2019. Locality domains and morphological rules: Phases, heads, nodesprouting and suppletion in Korean honorification. Natural Language and Linguistic Theory 37: 1319-1365.

Clemens, Lauren Eby. 2014. Prosodic noun incorporation and verb-initial syntax. PhD diss., Harvard University.

Clemens, Lauren. 2019. Prosodic noun incorporation: The relationship between prosody and argument structure in Niuean. Syntax.

Collins, Chris. 2002. Multiple verb movement in $\neq$ Hoan. Linguistic Inquiry 33(1): 1-29.

Collins, Chris. 1997. Argument sharing in serial verb constructions. Linguistic inquiry 28(3): 461-497.

Déchaine, Rose-Marie. 1993. Predicates across categories: Towards category-neutral syntax. PhD diss., UMass, Amherst.

Dixon, Robert M. W. 2006. Serial verb constructions: Conspectus and coda. In Serial verb constructions: A cross-linguistic typology, eds. Alexandra Y. Aikhenvald and Robert M. W. Dixon, 338-350. Oxford: Oxford University Press. 
Elfner, Emily. 2012. Syntax-prosody interactions in Irish. PhD diss., University of Massachusetts, Amherst.

Embick, David. 2010. Localism versus globalism in morphology and phonology. Linguistic inquiry monographs. Cambridge: MIT Press.

Embick, David, and Rolf Noyer. 2001. Movement operations after syntax. Linguistic Inquiry 32(4): 555595.

Ghini, Mirco. 1993. Phi-formation in Italian: A new proposal. Toronto Working Papers in Linguistics 12(2): 41-78.

Hale, Kenneth, Laverne M. Jeanne, and Paula M. Pranka. 1991. On suppletion, selection, and agreement. In Interdisciplinary approaches to language: Essays in honor of S.-Y. Kuroda, eds. Carol Georgopoulos and Roberta Ishihara, 255-270. Dordrecht: Kluwer.

Harry, Otelemate G., and Larry M. Hyman. 2014. Phrasal construction tonology: The case of Kalabari. Studies in Language 38(4): 649-689. https://doi.org/10.1075/sl.38.4.01hym.

Haspelmath, Martin. 2016. The serial verb construction: Comparative concept and cross-linguistic generalizations. Language and Linguistics 17(3): 291-319.

Henderson, Brent. 2011. Agreement, locality, and OVS in Bantu. Lingua 121(5): 742-753.

Henderson, Robert. 2012. Morphological alternations at the intonational phrase edge. Natural Language \& Linguistic Theory 30(3): 741-787.

Hopperdietzel, Jens. 2020. Resultatives: A view from Oceanic verb serialization. PhD diss., HumboldtUniversität zu Berlin.

Ingram, Andrew. 2006. Serial verb constructions in Dumo. In Serial verb constructions: A cross-linguistic typology, eds. Alexandra Y. Aikhenvald and Robert M. W. Dixon, 202-222. Oxford: Oxford University Press.

Inkelas, Sharon. 1989. Prosodic constituency in the lexicon. New York: Garland.

Inkelas, Sharon, and Draga Zec. 1990. The phonology-syntax connection. Chicago: University of Chicago Press.

Inkelas, Sharon, and Draga Zec. 1995. The syntax-phonology interface. In The handbook of phonological theory, ed. John A. Goldsmith, 535-549. Cambridge: Blackwell.

Kalin, Laura. 2018. Morphology before phonology: A case study of Turoyo (Neo-Aramaic). Ms., Princeton. lingbuzz/004258.

Kari, Ethelbert E. 2003. Serial verb constructions in Degema, Nigeria. African Study Monographs 244: 271-289.

Kari, Ethelbert E. 2004. A reference grammar of Degema. Cologne: Köppe.

Kastner, Itamar. 2019. Templatic morphology as an emergent property: Roots and functional heads in Hebrew. Natural Language and Linguistic Theory 37(2): 571-619. https://doi.org/10.1007/ s11049-018-9419-y.

Kilian-Hatz, Christa. 2006. Serial verb constructions in Khwe (Central-Khoisan). In Serial verb constructions: A cross-linguistic typology, eds. Alexandra Y. Aikhenvald and Robert M. W. Dixon, 108-123. Oxford: Oxford University Press.

Kinyalolo, Kasangati K. W. 1992. Syntactic dependencies and the spec-head agreement hypothesis in KiLega. PhD diss., UCLA.

McCarthy, John J. 2008. The gradual path to cluster simplification. Phonology 25: 271-319.

Myrberg, Sara. 2013. Sisterhood in prosodic branching. Phonology 30(1): 73.

Nespor, Marina, and Irene Vogel. 1986. Prosodic phonology. Berlin: Mouton de Gruyter.

Prince, Alan, and Paul Smolensky. 1993. Optimality theory: Constraint interaction in generative grammar. Technical Report RuCCS TR-2, Center for Cognitive Science, Rutgers University. Published (2004), Malden: Blackwell.

Pullum, Geoffrey K., and Arnold M. Zwicky. 1986. Phonological resolution of syntactic feature conflict. Language.

Richards, Norvin. 2016. Contiguity Theory. Cambridge: MIT Press.

Rolle, Nicholas. 2020. In support of an OT-DM model. Natural Language \& Linguistic Theory 38: 201259.

Rolle, Nicholas, and Ethelbert E. Kari. 2016. Degema clitics and serial verb constructions at the syntax/phonology interface. In Diversity in African languages, eds. Doris L. Payne, Sara Pacchiarotti, and Bosire Mokaya, 141-163. Berlin: Language Science Press.

Selkirk, Elisabeth. 1981. On prosodic structure and its relation to syntactic structure. In Nordic prosody II, ed. Thorstein Fretheim, 111-140. Trondheim: Tapir. 
Selkirk, Elisabeth. 1984. Phonology and syntax: the relation between sound and structure. Cambridge: MIT Press.

Selkirk, Elisabeth. 1996. The prosodic structure of function words. In Signal to syntax: bootstrapping from speech to grammar in early acquisition, eds. James L. Morgan and Katherine Demuth, 187214. Mahwah: Erlbaum.

Selkirk, Elisabeth. 2000. The interaction of constraints on prosodic phrasing. In Prosody: Theory and experiment, 231-261. Dordrecht: Springer.

Selkirk, Elisabeth. 2009. On clause and intonational phrase in Japanese: the syntactic grounding of prosodic constituent structure. Gengo Kenkyu 136: 35-73.

Selkirk, Elisabeth. 2011. The syntax-phonology interface. In The handbook of phonological theory, eds. John Goldsmith, Jason Riggle, and Alan Yu, 435-483. London: Blackwell.

Truckenbrodt, Hubert. 1995. Phonological phrases: Their relation to syntax, focus, and prominence. PhD diss., MIT.

Truckenbrodt, Hubert. 1999. On the relation between syntactic phrases and phonological phrases. Linguistic Inquiry 30(2): 219-255.

Tyler, Matthew. 2019. Simplifying MATCH WORD: Evidence from English functional categories. Glossa: A Journal of General Linguistics 4 (1).

Veenstra, Tonjes. 1996. Serial verbs in Saramaccan: Predication and creole genesis. Dordrecht: ICG Printing.

Veenstra, Tonjes, and Pieter Muysken. 2017. Serial verb constructions. The Wiley Blackwell companion to syntax, second edition. Publisher: Wiley Online Library.

Wolf, Matthew. 2008. Optimal Interleaving: Serial phonology-morphology interaction in a constraintbased model. PhD diss., University of Massachusetts, Amherst.

Zec, Draga. 2005. Prosodic differences among function words. Phonology 22(1): 77-112.

Zimmermann, Malte, and Mary Amaechi. 2018. Find construction analyze: Making sense of serial verb constructions. Handout from talk presented at the Goethe University Frankfurt. 